\title{
Catalytic Hydrogenation of Carbon Monoxide and Dioxide over Steel
}

\author{
BUFORD D. SMITH and ROBERT R. WHITE \\ University of Michigan, Ann Arbor, Michigan
}

The hydrogenation of carbon monoxide and carbon dioxide on various steel catalysts was studied in the temperature range of $800^{\circ}$ to $1,300^{\circ} \mathrm{F}$. and at pressures from 5 to $30 \mathrm{~atm}$. The feed gases ( 3.75 to $20 \mathrm{SCFH}$ ) were passed over a catalyst bed of $1 / 8$-in. steel balls supported in a brass-lined reactor $0.81 \mathrm{in}$. in diam. The percentage of carbon oxides in the feed was $30 \%$ in the runs using a $\mathrm{H}_{2}-\mathrm{CO}_{2}$ feed and varied from 15 to $38 \%$ in the runs with a $\mathrm{H}_{2}-\mathrm{CO}$ feed. The effects of temperature, pressure, feed composition, space velocity, and mass velocity were studied. Carbon deposition did not affect the activity of the catalyst and could be removed readily.

The catalytic hydrogenation of carbon monoxide and carbon dioxide has received intensive study since the turn of the century. In 1897 and 1902 Sabatier and Senderens $(15,16)$ reported their original work on the synthesis of methane from hydrogen-carbon monoxide and hydrogen-carbon dioxide mixtures in the presence of both reduced nickel and reduced cobalt catalysts. In 1923 Fisher and Tropsch (8) disclosed that iron was also an effective catalyst. Storch et al. (18) summarized these early discoveries and the investigations that followed.

Table 1. Steel Catalyst Compositions (Weight \%)

\begin{tabular}{lccc} 
Constituent & \multicolumn{3}{c}{ S. A. E. number } \\
Carbon & C1013 & 440 & 302 \\
Chromium & $0.13-0.18$ & $0.86-0.94$ & $0.08-0.20$ \\
Manganese & - & $16.5-18.0$ & $17.0-19.0$ \\
Silicon & $0.50-0.80$ & $0.30-0.60$ & 2.0 \\
Sulfur & - & 0.60 max. & 1.0 max. \\
Phosphorus & 0.05 max. & 0.30 max. & 0.03 max. \\
Molybdenum & 0.04 max. & 0.30 max. & 0.04 max. \\
Nickel & - & $0.40-0.60$ & \\
& - & - & $8.0-10.0$
\end{tabular}

Buford D. Smith is with Humble Refining Company, Baytown, Texas.

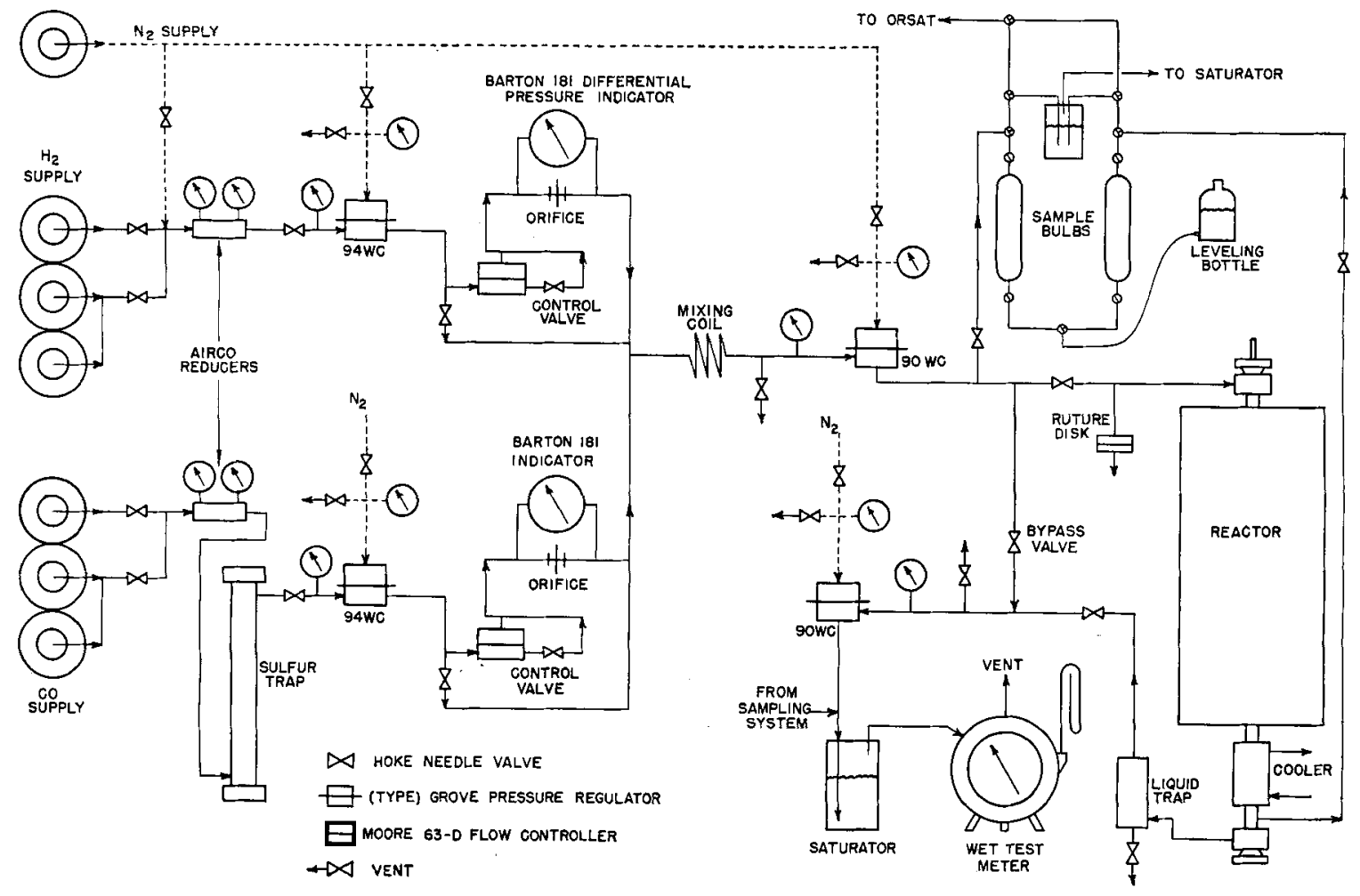

Fig. 1. Flow diagrams for the experimental unit. 


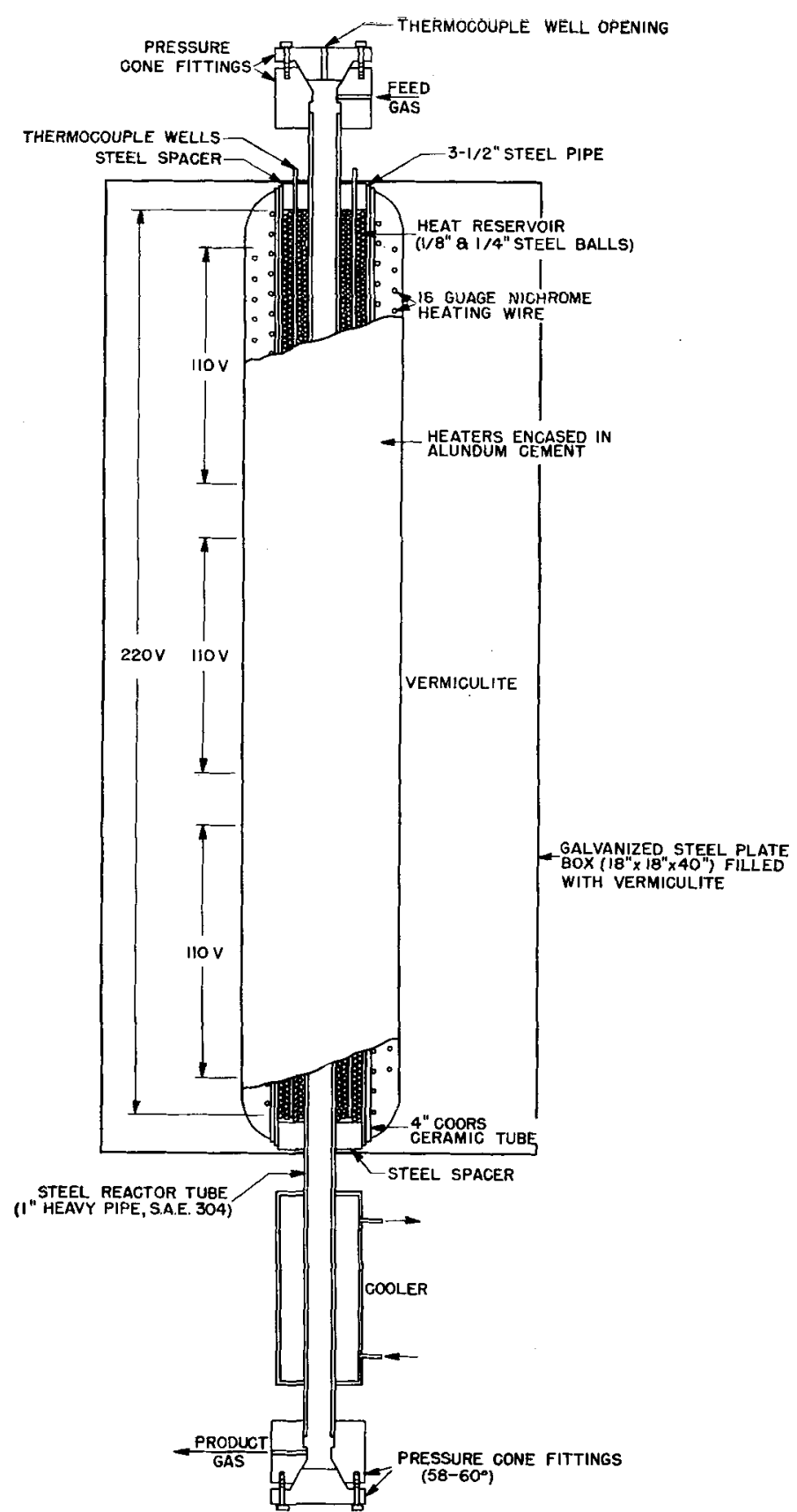

Fig. 2. Cross-sectional drawing of the reactor and cooler.

Table 2 Catalyst Comparison Runs

(Typical Portion of Data)

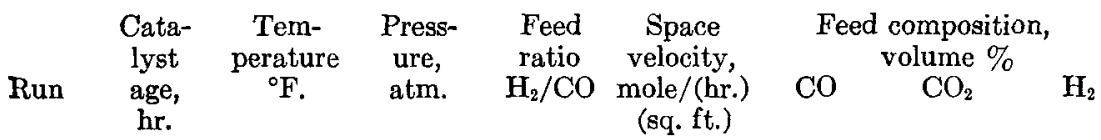

Catalyst: C1013, unpolished and untreated, 194 balls (0.0661 sq. ft. of surface)

$\begin{array}{lllllllll}\text { D33 } & 2.7 & 1053 & 30 & 2.3 & 0.20 & 30.6 & 0.2 & 69.2 \\ \text { D34 } & 3.8 & 1048 & 30 & 2.3 & 0.20 & 30.6 & 0.2 & 69.2 \\ \text { D35 } & 4.4 & 1051 & 30 & 2.3 & 0.20 & 30.6 & 0.2 & 69.2 \\ \text { D36 } & 5.2 & 1050 & 30 & 2.3 & 0.20 & 30.6 & 0.2 & 69.2\end{array}$

A number of investigations have been directed toward the production of methane from carbon monoxide, carbon dioxide, and hydrogen. The results of a British project to upgrade town gas by synthesizing methane from coal gas have been periodically reported $(11,6,12)$. Commercial processes have been outlined in the literature $(10,5,2)$. Intensive kinetic studies of the synthesis of methane on nickel catalysts from hydrogen-carbon monoxide $(1,14)$ and hydrogen-carbon dioxide $(4,7)$ have been made recently.

Recently (9) stainless stcel pipe was reported to be an effective methanization catalyst in the temperature range of $950^{\circ}$ to $1,500^{\circ} \mathrm{F}$. The use of finely divided stainless steel particles at lower temperatures to synthesize gasoline has been disclosed (13).

The high catalytic activity per unit of surface area shown by steel at $950^{\circ}$ to $1,500^{\circ} \mathrm{F}$. suggests that the greater surface area of a porous catalyst might be sacrificed to obtain the greater mechanical strength of nonporous-steel catalyst particles. Catalyst crumbling and sintering would be eliminated, making possible more severe operating and carbonremoval conditions. This work is a study of the hydrogenation reactions on such a catalyst in the form of $1 / 8$-in. steel spheres.

\section{EXPERIMENTAL EQUIPMENT}

A flow diagram of the experimental unit appears in Figure 1. Commercial gas cylinders (size 1A) were used as the feed-gas source with activated charcoal being used to remove the sulfur from the carbon monoxide. The two feed streams were metered and controlled separately.

The feed streams were mixed before leaving the control system. A wet test meter furnished accurate measurements of the feed and product rates, and the sampling system provided samples of the feed and product streams for Orsat and infrared analyses.

The reactor (Figure 2) consisted of an electrically heated, insulated stainless steel pipe. Steel balls around the reactor pipe provided a large sensible heat reservoir and facilitated the maintenance of a constant reactor temperature. Thermocouple wells provided entry for two iron-constantan couples into the mass of steel balls. A brass liner (not shown) extended the full length of the reactor tube to mask the catalytic steel surface. The copper-covered steel thermocouple well shown in Figure 3 passed through the top pressure cone fitting and supported the catalyst support at a point about 6 in. below the middle of the insulated section of the reactor. A Brown potentiometer measured the bed temperature as indicated by an iron-constantan couple placed within this well.

\section{MATERIALS}

Aluminum tubing, steel Ermeto fittings, and Hoke needle valves with steel bodies were used in the experimental apparatus.

The feed gases were obtained commer- 
cially. According to the supplier's analyses the hydrogen (electrolytic) had a purity of $99.9 \%$ with less than $0.1 \%$ oxygen; the carbon monoxide was $96.8 \%$ pure with $1 \%$ nitrogen, $0.36 \%$ carbon dioxide, $0.97 \%$ hydrogen, $0.8 \%$ hydrocarbons, and 0.3202 $\mathrm{mg}$./liter of sulfur; and the carbon dioxide contained only $0.5 \%$ air as an impurity.

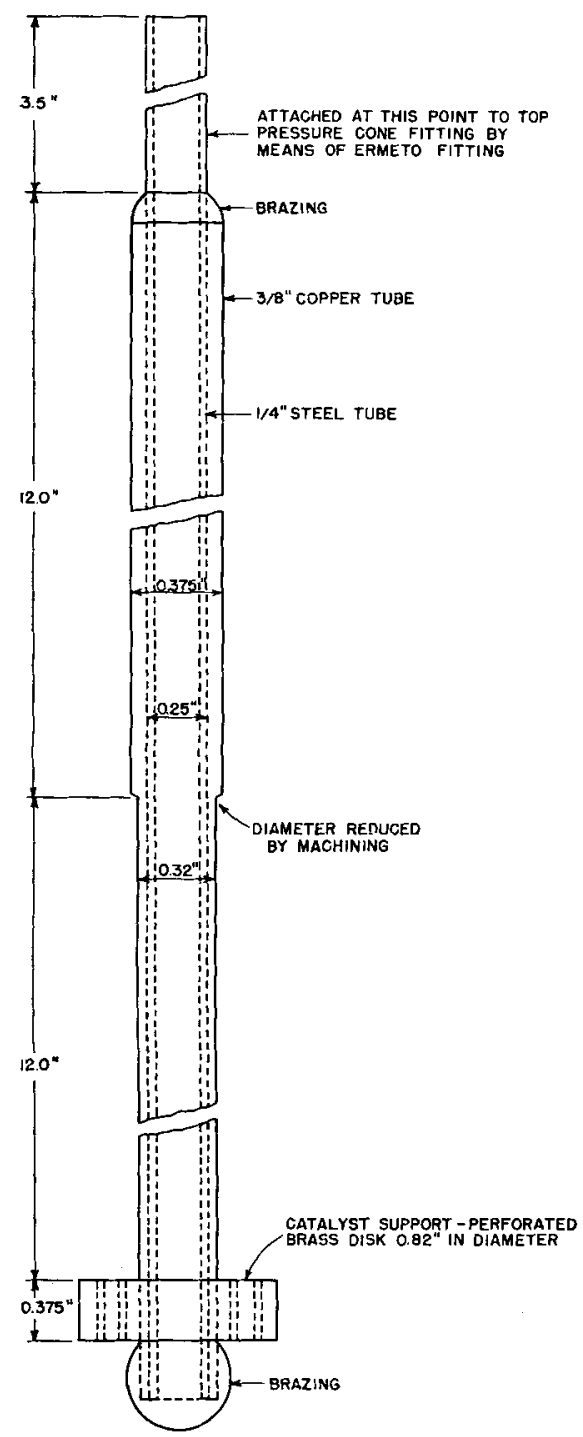

Fig. 3. Thermocouple well and catalyst support.
The methane and helium had purities of 99 and $99.99 \%$ respectively.

Three S. A. E. steel alloys (C1013, 440, and 302) were used as catalysts in the form of $1 / 8$-in. balls. Their chemical compositions are listed in Table 1.

\section{ANALYTICAL METHODS}

A conventional Orsat apparatus using a $33 \%$ sodium hydroxide solution was used for the carbon dioxide analyses. Carbon monoxide, methane, and ethane concentrations in the gas samples were determined with a Baird model $B$ recording infrared spectrophotometer. The hydrogen in the gas streams was determined by subtracting the volume of the other gaseous constituents from the total gas volume. All analyses were on a water-free basis. The water produced in a run was calculated by making

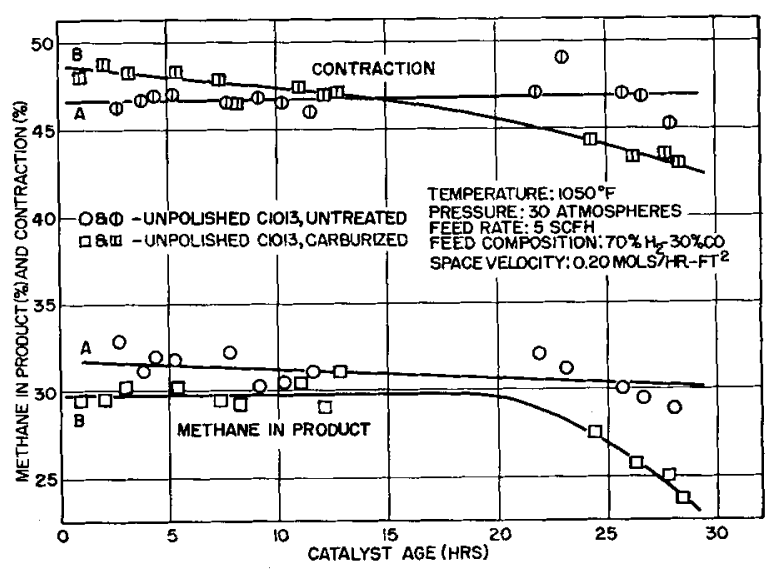

Fig. 4. Effect of carburization on the percentage of contraction and methane produced by the unpolished $\mathrm{C} 1013$ steel balls.

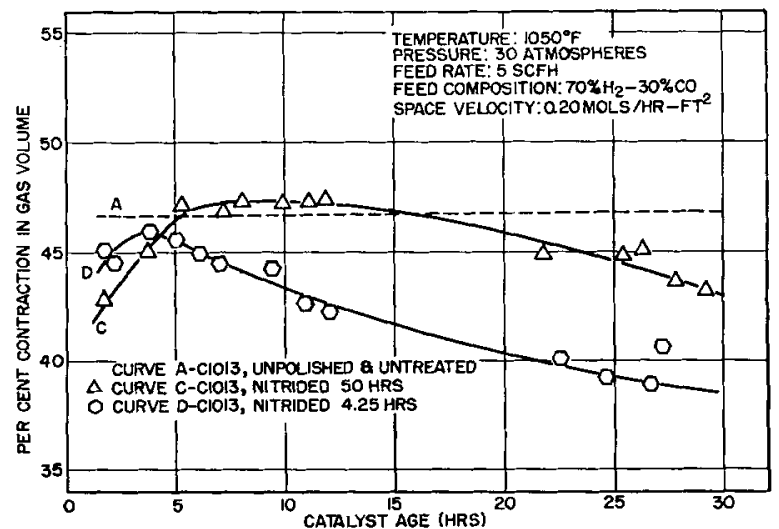

Fig. 5. Effect of nitriding on the percentage of contraction obtained with the unpolished C1013 steel balls.

Table 3. Evaluation of the Untreated C1013 Stegl Catalyst (Typical Portion of Data)

\section{Space}

velocity,

Catalyst Temper- Pressure, Feed ratio moles/

Run age, $\mathrm{hr}$. ature, ${ }^{\circ} \mathrm{F}$. atm. $\mathrm{H}_{2} / \mathrm{CO} \quad \mathrm{H}_{2} / \mathrm{CO}_{2}(\mathrm{hr}$.
Catalyst bed: 194 steel balls $(0.0661$ sq. $\mathrm{ft}$. of surface $)$

T2

T3

P1

P4

F1

F4

A9

$\mathrm{A} 12$
2.3
847
30
30
- $\quad 2.3$
2.3
0.20

atalyst bed: 194 steel balls (0.0661 sq. ft. of surface)
3.5
1,070
30
2.4
-
0.20
$5.1 \quad 1,070$
20
2.4
0.20

Catalyst bed: 194 steel balls (0.0661 sq. $\mathrm{ft}$. of surface)
$2.7 \quad 1,069$
30
5.5
$-\quad 0.20$
$-\quad 0.20$

Catalyst bed: 388 steel balls (0.1322 sq. ft. of surface)
3.5
1,060
30
30
2.5
-
0.10
0.13

Feed composition, volume $\%$

$\mathrm{CO} \stackrel{\mathrm{CO}_{2}}{\mathrm{CO}_{2}} \stackrel{\mathrm{H}_{2}}{\mathrm{CH}_{4}}$
30.4

30.7

29.0

29.0

15.4

18.9

28.6

29.1

\section{0.}

$$
0.2
$$

0.2

0.2

0.2

0.2
0.2
69.6

69.3

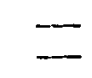

70.0

70.0

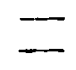

84.1

80.5

$-\quad 5.05$

70.5

69.9
5.05

3.64

Gas flow rates, std. cu. ft./hr. Feed Product

5.02 5.00

4.97 4.89

5.00

2.76

2.87

4.36

3.64

2.71

3.65 
both an oxygen and a hydrogen balance and averaging the two results.

\section{EXPERIMENTAL METHOD}

The first part of the experimental work was concerned with the selection of the best combination of steel composition and catalyst pretreatment. These pretreatments consisted of nitriding, carburizing, and deformation of the steel catalyst surfaces.

The nitriding was accomplished in a small tubular furnace at $1,000^{\circ} \mathrm{F}$. with the dissociation of the ammonia maintained at approximately $30 \%$. Precautions were taken to remove oil films from the steel by washing with benzene. Oxide films were removed from the chromium-containing steels by treatment with a $50 \%$ hydrochloric acid solution at $150^{\circ} \mathrm{F}$. for 3 to $10 \mathrm{~min}$.

The carburization treatment was given only to some C1013 steel balls, increasing their carbon content to $0.9 \%$. Highly polished $\mathrm{C} 1013$ and 302 steel ball bearings were also obtained so as to determine the effect of surface deformation on the catalytic activity of the steel.

Samples of these various steel catalysts were tested in the reactor under identical conditions. During these comparison runs ( $D$ runs) the reactor was maintained at temperature and the catalyst dropped directly into the hot reactor. The reactor was flushed with hydrogen, the catalyst was charged, and the flow of synthesis gas started immediately.

In the remainder of the experimental work the catalyst was put in the reactor at room temperature and heated slowly to the desired temperature under a flow of synthesis gas. The age of the catalyst was considered as zero when the reactor first reached the run temperature.

The steel catalyst balls were always mixed with an equal number of $1 / 8$-in. brass balls to facilitate the removal of heat. Layers of brass balls above and below the catalyst bed served to eliminate entrance and exit effects.

The important data and samples taken for each run are summarized below.

1. Run number, date, and hour.

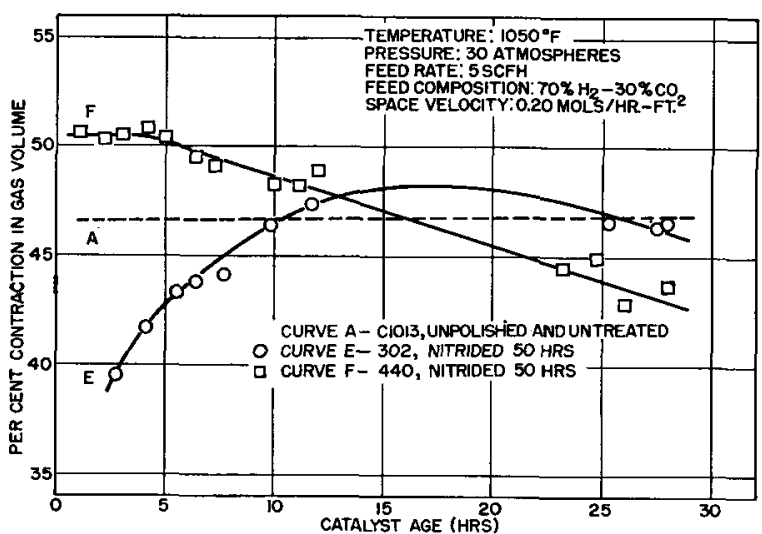

Fig. 6. Comparison of the nitrided 302 and 440 steel balls with the untreated $\mathrm{C} 1013$ balls.

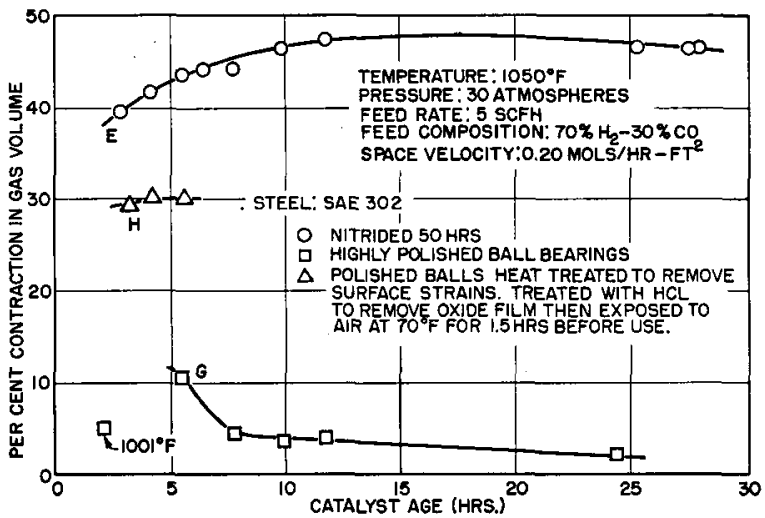

Fig. 7. Effect of various surface treatments on the catalytic activity of the 302 steel.

Table 4. Mechanism Studies with the Untreated C1013 Steel Catalyst (Typical Portion of Data)

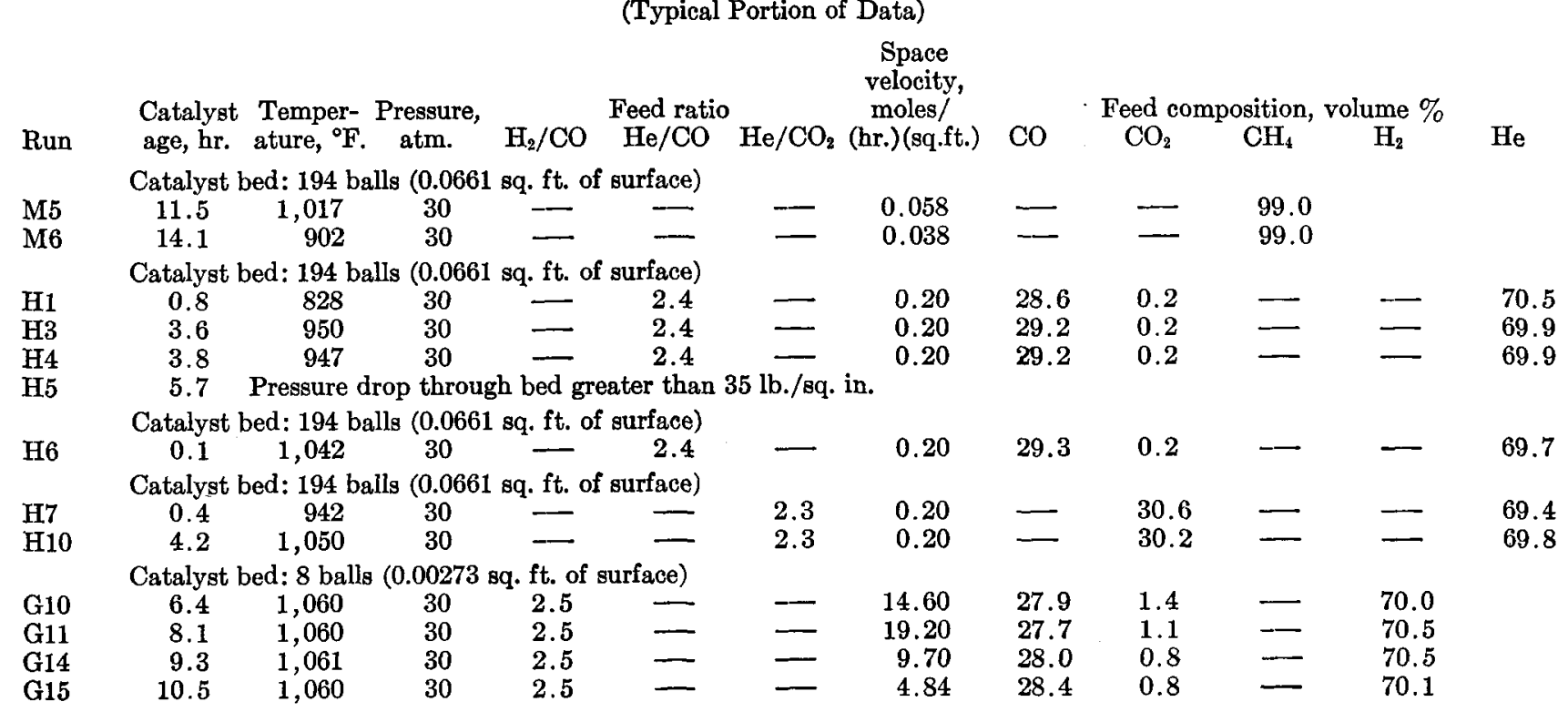


2. Catalyst type, amount, and pretreatment.

3. Reactor pressure.

4. Catalyst bed temperature.

5. Wet test meter data (time per revolution for feed and product streams, gas temperature, and pressure).

6. Samples for Orsat and infrared analyses.

\section{EXPERIMENTAL DATA}

Samples of the various steel catalysts were tested in the reactor under the following conditions:

$\begin{array}{ll}\text { Temperature } & 1,050^{\circ} \mathrm{F} . \\ \text { Pressure } & 30 \mathrm{~atm} . \\ \text { Feed rate } & 5 \text { std. cu. ft. } / \mathrm{hr} . \\ \text { Feed composition } & 70 \% \mathrm{H}_{2}-30 \% \mathrm{CO} \\ \text { Catalyst surface } & 0.0661 \text { sq. ft. (194 ball }\end{array}$

Catalyst surface 0.0661 sq. ft. (194 balls)

A typical portion of the data obtained in these comparison runs is shown in Table 2. The percentage of contraction in the feed-gas volume was the criterion of catalyst activity used. Product analyses were obtained, however, to show that no significant difference in product distribution existed between the various catalysts.

The results of the comparison runs permitted the selection of the most effective catalyst, and the next portion of the experimental work was devoted to its evaluation. Typical portions of the runs in which the effect of temperature $T$, pressure $P$, feed composition $F$, and space velocity $A$ were determined appear in Table 3 , in which each group of runs was made with a different batch of catalyst.

The final part of the experimental work was a study of the rate-controlling steps and the basic reaction paths in the hydrogenation of carbon monoxide and carbon dioxide. The results obtained with a pure methane feed are listed in Table 4 as the $M$ runs. Part of the data from a study of the reactions $\mathrm{CO}=\mathrm{CO}_{2}+\mathrm{C}$ and $\mathrm{CO}_{2}=\mathrm{CO}+1 / 2 \mathrm{O}_{2}$ in which helium was substituted for hydrogen is included as the $H$ runs, and the $G$ runs show the effect of mass velocity on the rates of reaction. Complete experimental data are available elsewhere $(17)$.

\section{MATERIAL BALANCES}

Carbon balances were made for 175 of the experimental runs. Of these, only $23.4 \%$ had an error greater than $\pm 5 \%$, and $60 \%$ had an error of less than $\pm 3 \%$.

\section{DISCUSSION OF RESULTS}

\section{Catalyst-comparison Studies}

The results of the catalyst-comparison runs appear in Figures 4 through 7 . Figure 4 shows the effect of carburization on the methane produced and the contraction in gas volume obtained with the C1013 steel. Figures 5 and 6 compare the nitrided C1013, 440, and 302 steels to the untreated C1013, represented by the dotted lines. The nitrided catalysts, with the exception of the 440 steel, exhibited an initial increase in activity. The heavily nitrided $\mathrm{C} 1013$ and 302 balls had almost no catalytic activity at time zero, indicating that excessive nitrogen can destroy the catalytic activity of the steel.

Tukon diamond pyramid hardnesses taken across a center plane of the nitrided steel balls before and after use in the reactor indicated a rapid loss of nitrogen during the synthesis period. Part of the hardness measurements from the nitrided
Table 5. Hardness of Nitrided C1013 Stegl Balus Before and After Use in THE ReACtor

\begin{tabular}{ccccc}
$\begin{array}{c}\text { Distance } \\
\text { from }\end{array}$ & \multicolumn{2}{c}{$\begin{array}{c}\text { Nitrided } \\
4.25 \mathrm{hr} .\end{array}$} & \multicolumn{2}{c}{$\begin{array}{c}\text { Nitrided } \\
50 \mathrm{hr} .\end{array}$} \\
$\begin{array}{c}\text { surface, } \\
\text { mm. }\end{array}$ & Before & After & Before & After \\
0.02 & 289 & 104 & - & 448 \\
0.05 & 288 & 107 & - & 445 \\
0.10 & 270 & 110 & 500 & 400 \\
0.30 & 214 & 120 & 175 & 109 \\
0.50 & 175 & - & 150 & 122 \\
0.70 & 168 & - & 127 & 123
\end{tabular}

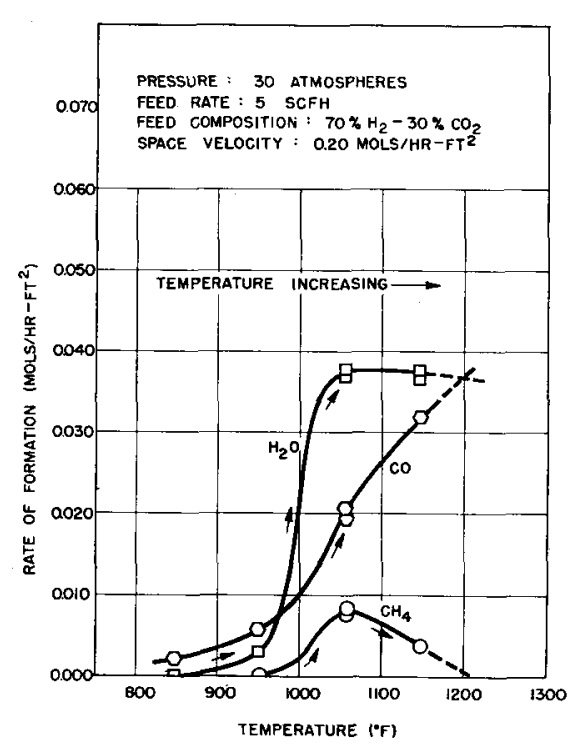

Fig. 8a. Effect of increasing temperature on the reaction rates obtained with a $\mathrm{H}_{2}-\mathrm{CO}_{2}$ feed.

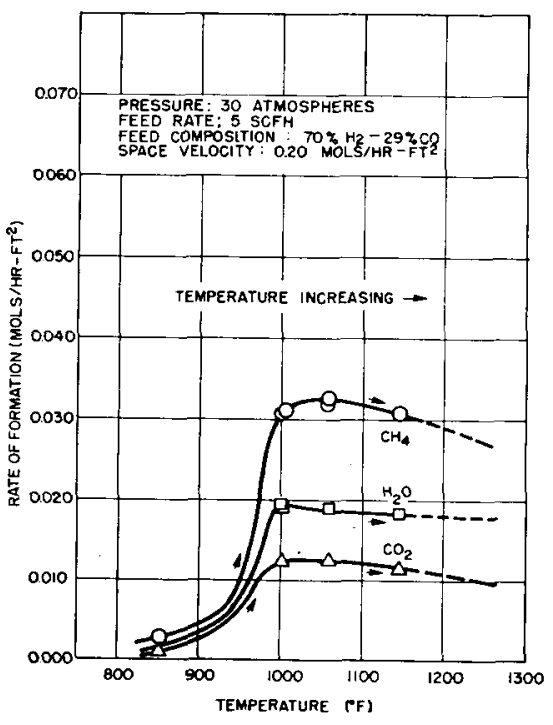

Fig. 9a. Effect of increasing temperature on the reaction rates obtained with a $\mathrm{H}_{2}-\mathrm{CO}$ feed.

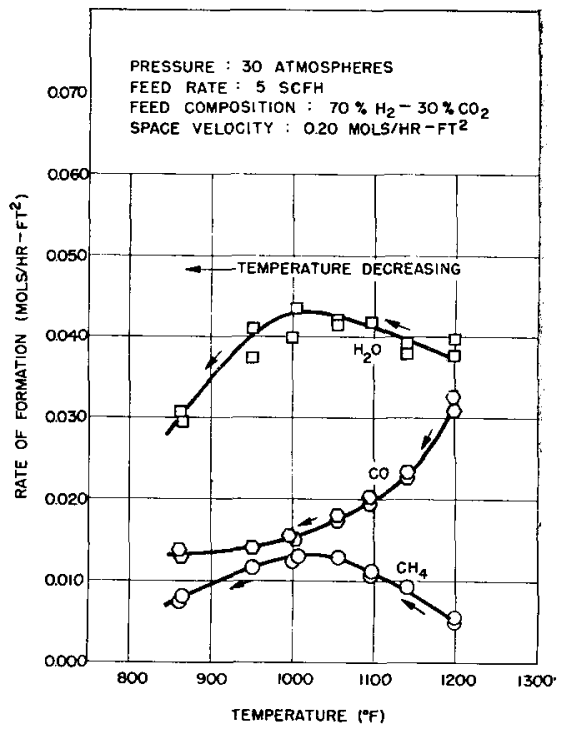

Fig. 8b. Effect of decreasing temperature on the reaction rates obtained with a $\mathrm{H}_{2}-\mathrm{CO}_{2}$ feed.

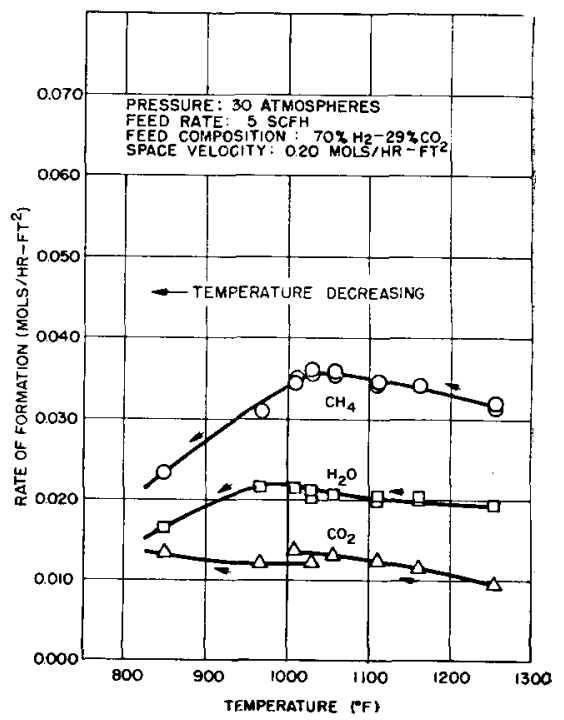

Fig. 9b. Effect of decreasing temperature on the reaction rates obtained with a $\mathrm{H}_{2}-\mathrm{CO}$ feed. 

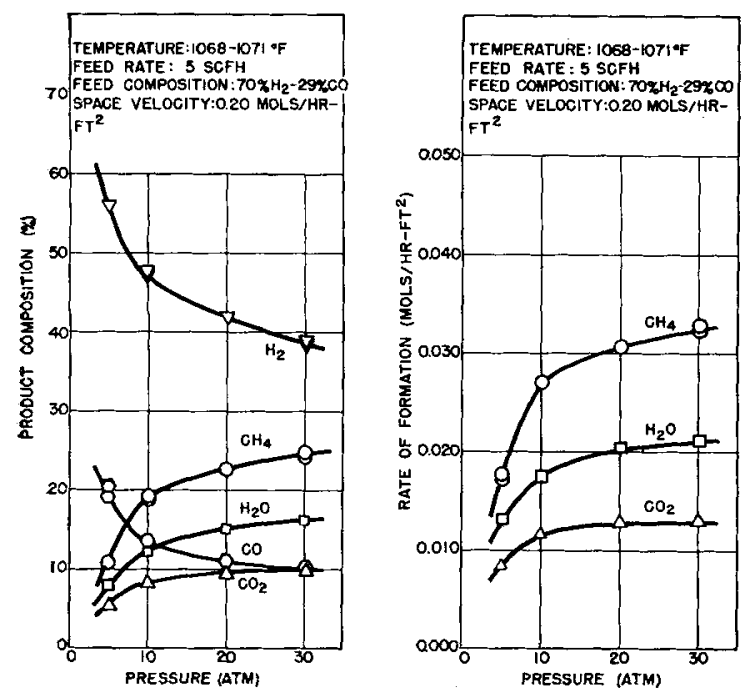

Fig. 10a. Effect of pressure on the product obtained with on the re a $\mathrm{H}_{2}-\mathrm{CO}$ feed.

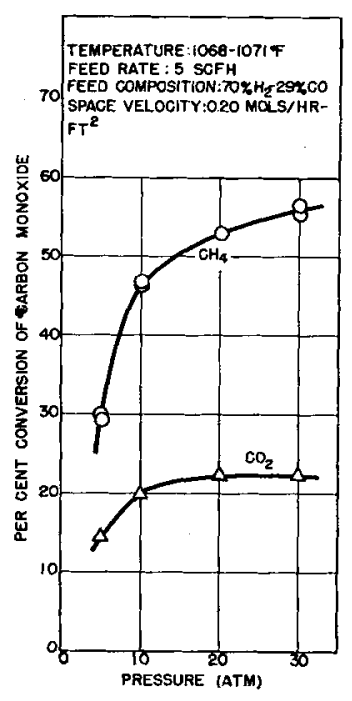

Fig. 10c. Effect of pressure on the conversions obtained with a $\mathrm{H}_{2}-\mathrm{CO}$ feed.

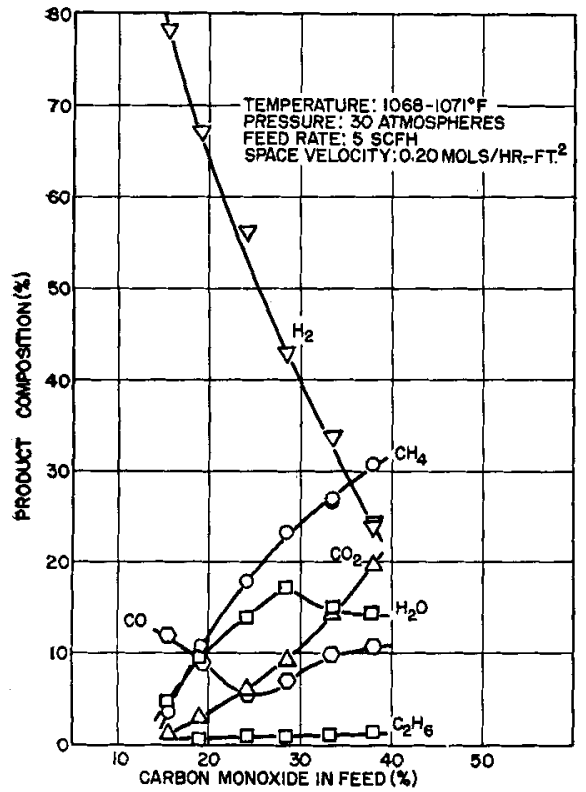

Fig. 11. Effect of varying the feed carbon monoxide concentration on the product obtained with a $\mathrm{H}_{2}-\mathrm{CO}$ feed.

C1013 steel balls appears in Table 5 . The loss of nitrogen is probably associated with the increase in activity with the maximum activity corresponding to an optimum amount of nitrogen. The behavior of the 440 steel is perhaps explained by assuming that it contained the optimum amount of nitrogen at the beginning of the test period.

Anderson et al. ( $(3)$ in their work with a nitrided synthetic-ammonia iron catalyst reported that carbon replaced the nitrogen in the iron lattice. This is probably the reason for the serious deactivation of the nitrided catalysts in the later portion of the test period.
Figure 7 shows the effect of various surface treatments on the catalytic activity of the 302 steel. The polished balls exhibited a low activity, probably owing to the protective oxide film on stainless steel. The reactor temperature of $1,050^{\circ} \mathrm{F}$. probably relieved the surface strains due to polishing, but the reduction of the chromium oxide film on stainless steel is unlikely under the reactor conditions. A heat treatment to remove surface strains followed by a treatment to remove the oxide film resulted in an increase in activity for the 302 steel, but it remained inferior to the untreated C1013

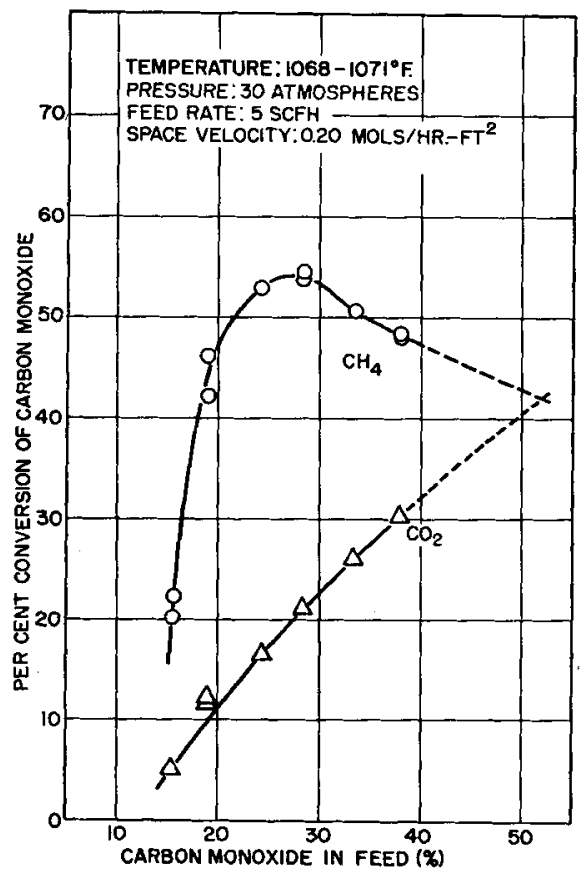

Fig. 12. Effect of varying the feed carbon monoxide concentration on the percentage of conversion of carbon monoxide to methane and carbon dioxide. steel. Again this lower activity was attributed to the formation of a light oxide film during the $1.5 \mathrm{hr}$. of exposure to air between the hydrochloric acid treatment and the introduction of the catalyst into the reactor. Nitriding the 302 steel probably destroyed the oxide film and resulted in an activity comparable with that of the untreated C1013 steel.

Polishing the C1013 steel had a temporary inhibiting effect on its catalytic activity. The steel exhibited almost no catalytic activity during the first $40 \mathrm{~min}$. in the reactor and then suddenly became active. No conclusions could be drawn as to whether the surface distortion or an oxide film was responsible as $40 \mathrm{~min}$. at the reactor conditions would be sufficient to eliminate both in this case.

The results of the catalyst comparison runs showed that ordinary carbon steel (C1013) was superior to stainless steel. Carburizing, nitriding, and surface-distortion treatments had a deleterious effect on the activity of the C1013 steel. Nitriding the 440 and 302 steels failed to produce a catalyst superior to the plain C1013 steel. The untreated, unpolished C1013 steel was therefore chosen as the most effective catalyst of those tested.

\section{Evaluation of the Untreated C1013 Steel Catalyst}

Effect of Temperature. The effect of temperature on the reaction rates obtained on the C1013 catalyst with $\mathrm{H}_{2}-\mathrm{CO}_{2}$ and $\mathrm{H}_{2}-\mathrm{CO}$ feeds appears in Figures 8 and 9 . In both cases the points were taken in the order of increasing temperature until $1,200^{\circ}$ or $1,250^{\circ} \mathrm{F}$. was reached. The reactor was allowed to operate at that temperature for $12 \mathrm{hr}$. before the decreasing-temperature curves were started. On the way down another 12-hr. period of constant temperature occurred at approximately $1,000^{\circ} \mathrm{F}$. in both cases. The 12-hr: period above $1,200^{\circ} \mathrm{F}$. resulted in an increase in catalyst effectiveness causing the decreasing temperature curves for methane to lie above the increasing temperature curves for that constituent. The $12-\mathrm{hr}$. period at $1,000^{\circ} \mathrm{F}$. caused only minor changes in the catalyst activity. A similar independence of time is exhibited by the C1013 steel at $1050^{\circ} \mathrm{F}$. in Figures 4 and 18.

Comparison of Figures 8 and 9 illustrates the difference in product distribution obtained with $\mathrm{H}_{2}-\mathrm{CO}_{2}$ and $\mathrm{H}_{2}-\mathrm{CO}$ feeds. With a $\mathrm{H}_{2}-\mathrm{CO}_{2}$ feed the principal products in the order of their abundance were water, carbon monoxide, methane, and ethane. With a $\mathrm{H}_{2}-\mathrm{CO}$ feed, methane became the most abundant product, followed by water, carbon dioxide, and ethane in that order. The rate of formation of methane at $1,050^{\circ} \mathrm{F}$. was four times as great with a $\mathrm{H}_{2}-\mathrm{CO}$ feed. Both feeds gave carbon deposition.

The rates of reaction experience a 


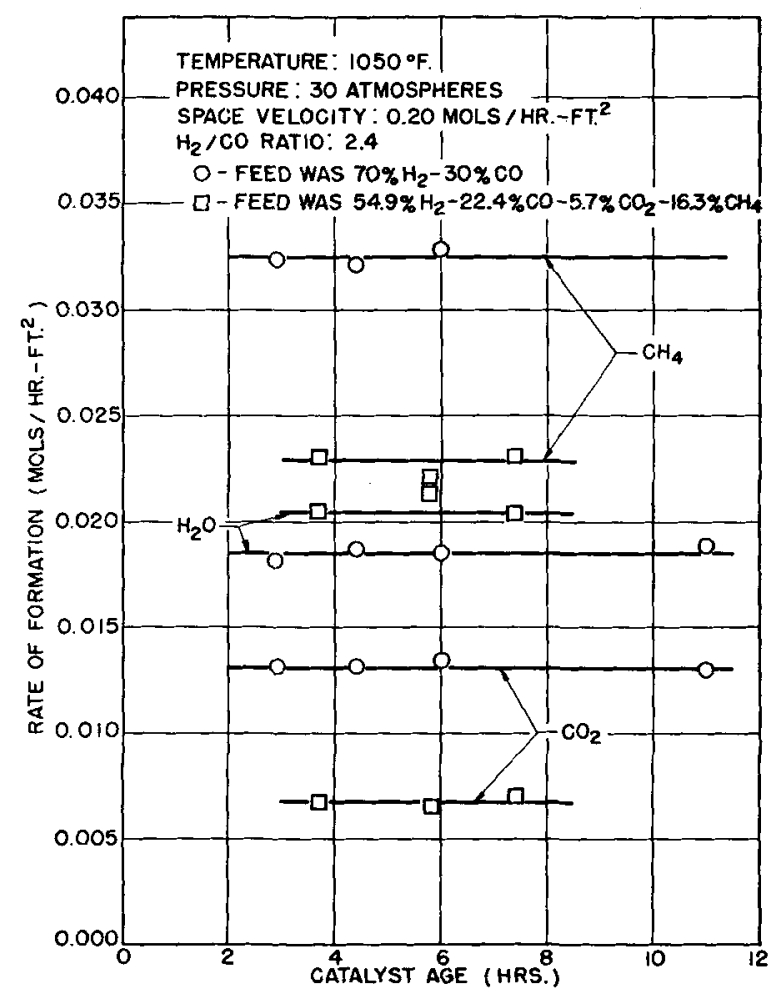

Fig. 13. Effect on the reaction rates caused by the addition of methane and carbon dioxide to a $\mathrm{H}_{2}-\mathrm{CO}$ feed.

TABLE 6

Mass velocity, lb. $/($ hr.) (sq. ft.)

CO
28.4
28.0
27.9
27.7

Feed,
$\mathrm{CO}_{2}$
0.8
0.8
1.4
1.1

$\mathrm{H}_{2}$

70.1

70.5

70.0

70.5

Product,
$\mathrm{CH}_{4}, \%$
3.4
1.9
1.4
1.2

Order of taking

4

3

1
1.4
1.1

1.2

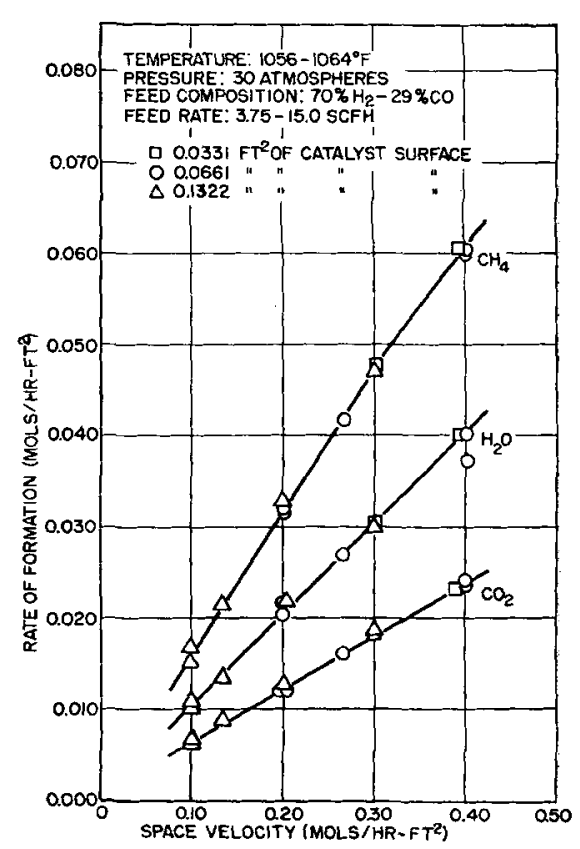

Fig. 14. Effect of varying the space velocity on the reaction rates obtained with a $\mathrm{H}_{2}-\mathrm{CO}$ feed.

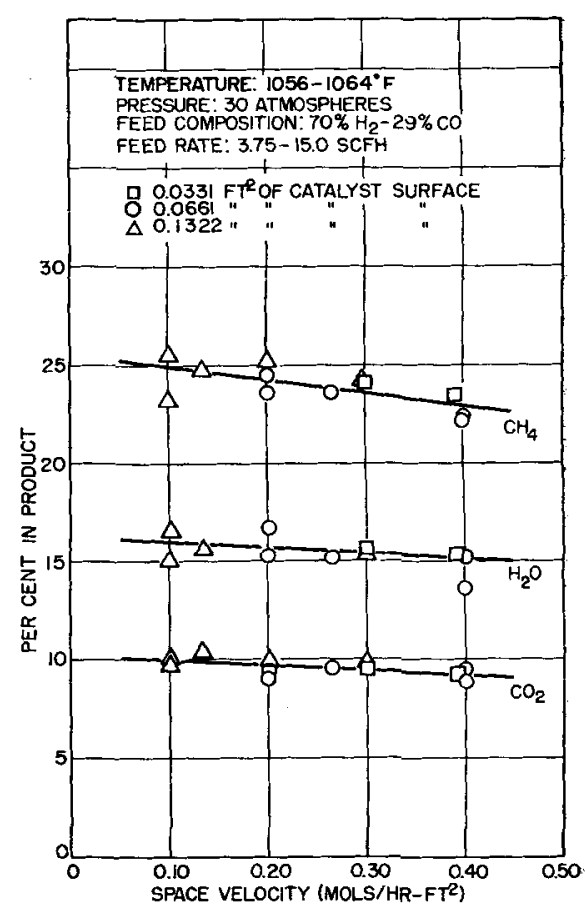

Fig. 15. Effect of varying the space velocity on the product obtained with a $\mathrm{H}_{2}-\mathrm{CO}$ feed. ever, increasing the amount of carbon monoxide in the feed is not so advantageous as this figure alone would indicate. In addition to the difficulty of increased carbon deposition, the fractional conversion of the carbon monoxide to methane begins to decrease above $27 \%$ carbon monoxide in the feed. This is illustrated in Figure 12. Extrapolation of the curves in Figure 12 indicates that the conversion to carbon dioxide would equal the conversion to methane at a $\mathrm{H}_{2} / \mathrm{CO}$ feed ratio of approximately 1 .

The effect of adding methane and carbon dioxide to a $\mathrm{H}_{2}-\mathrm{CO}$ feed is summarized in Figure 13. The $\mathrm{H}_{2} / \mathrm{CO}$ ratio was 2.4 for both the $\mathrm{H}_{2}-\mathrm{CO}$ and mixed feeds. The addition of methane and carbon dioxide to the feed decreased the rates of formation of those two compounds by 29 and $48 \%$ respectively. The rate of formation of water was increased by approximately $10 \%$. Carbon deposition was heavier with the mixed feed, indicating that the ratio $\mathrm{H}_{2} /\left(\mathrm{CO}+\mathrm{CO}_{2}\right)$ is more important in predicting carbon formation than the $\mathrm{H}_{2} / \mathrm{CO}$ ratio. 


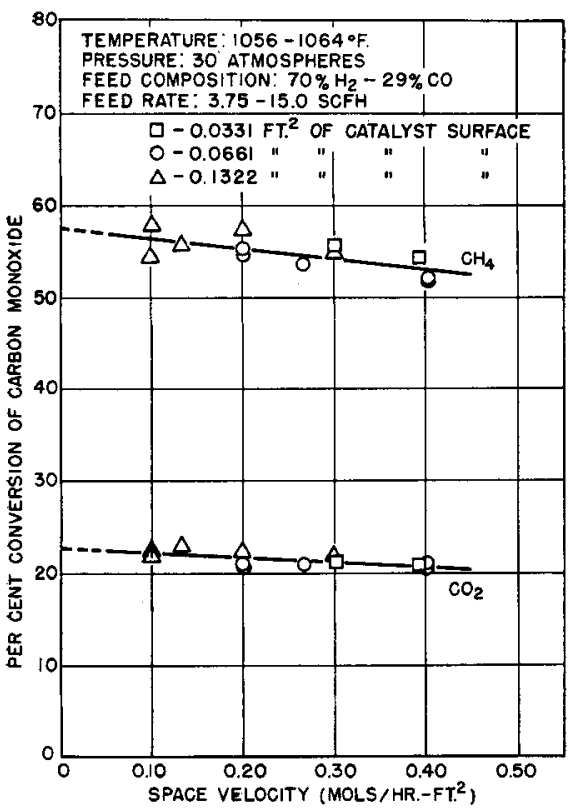

Fig. 16. Effect of varying the space velocity on the conversion of the feed carbon monoxide to methane and carbon dioxide.

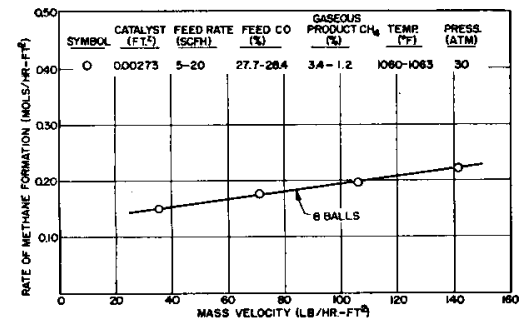

Fig. 17. Effect of varying the space velocity on the rate of methane formation.

The large percentage decrease in the carbon dioxide formation rate caused by a relatively small amount of that constituent in the feed is encouraging. The ratio of the rate of methane formation to that of carbon dioxide was 3.4 for the mixed feed compared with 2.5 for the $\mathrm{H}_{2}-\mathrm{CO}$ feed. An even more favorable ratio would probably have occurred if methane had not also been added with the carbon dioxide.

Effect of Space Velocity. The space velocity was defined as total moles $\mathrm{fed} /$ hour/square foot of catalyst surface in order to make it independent of catalyst-particle size.

The expression of average reaction rates or conversions as a function of space velocity eliminates bed depth as a variable. This was demonstrated by varying the space velocity by (1) changing the amount of gas flowing over a given number of balls and (2) holding the gas flow constant while the number of balls varied. The results are shown in Figures 14, 15, and 16. The number of balls (and the bed depths) used varied fourfold, and the flow rates ranged from 3.75 to 15.0 std. cu. ft./hr. Figure 14 shows that bed depth or mass velocity

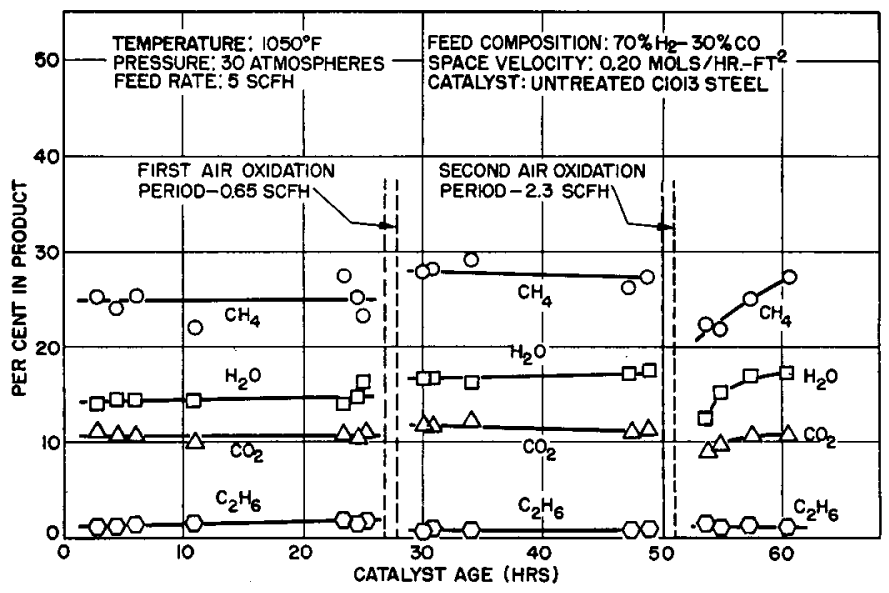

Fig. 18. Effect of regeneration by oxidation on product formation.

had no appreciable effect on the average reaction rates obtained at a given space velocity. Mass velocity does have an effect on the initial reaction rate, as shown later, but in these runs made with an integral reactor the effect is masked by the excessive bed depths used.

The product distribution remained essentially constant over the range of space velocity studied (Figure 15).

Extrapolation of the curves in Figure 16 to zero space velocity indicates that the maximum possible conversion of the carbon monoxide to methane and carbon dioxide is $\mathbf{5 7 . 5}$ and $22.5 \%$ respectively. Approximately $2 \%$ of the carbon monoxide would be converted to ethane, giving a total conversion of about $82 \%$. This is considerably less than the conversion indicated by equilibrium calculations.

Effect of Mass Velocity. The rate of mass transfer of reactant and product molecules to and away from the catalyst surface is a function of the mass velocity of the gases through the catalyst bed. If mass transfer is the rate-controlling step in the over-all reaction, then the reaction rates are a function of mass velocity.

The mass velocity through a differential bed (eight balls) was varied fourfold to determine the effect on the reaction rates. A differential bed was used to give small conversions so that the composition of the reacting system was substantially independent of feed rate. Table 6 lists the feed concentrations, the methane produced, and the order of the four points shown in Figure 17. Figure 17 shows an increasing reaction rate with increasing mass velocity. If the small variation in the carbon monoxide concentration of the feed had been absent, the slope of the curve would have been greater.

The order eliminated any effect of time on the experimental results. The conversion, with the possible exception of the first run, was low enough to eliminate the effect of changing concentration potentials. Therefore, the increase in the rates of formation of methane with increasing mass velocity is probably due to the smaller resistance to mass transfer at the higher gas velocities. This indicates that mass transfer may be partially a rate-controlling step in the over-all reaction process.

At first glance, Figure 17 appears to contradict the conclusions drawn from Figure 14, namely, that the rate of formation of methane was independent of mass velocity at any given value of space velocity. No contradiction exists; the effect of mass velocity is simply masked when bed depths great enough to push the reaction close to completion are used. In that situation a change in reaction rate in the first increment of bed depth caused by a change in mass velocity is compensated for. in the latter part of the bed. This was the case in the data shown in Figure 14. Figure 16 shows the almost negligible effect of quadrupling the bed size on the conversion obtained, indicating that even in the smallest bed the bottom portion of the catalyst supported only a small part of the total reaction and was always available to compensate for any change in reactivity of the top portion.

Removal of Carbon by Oxidation with Air. A series of runs was made to investigate the possibility of removing the carbon from the catalyst by oxidizing it with air. The results of these runs appear in Figure 18.

The reactor pressure was reduced to 1 atm. and the synthesis gas flushed from the reactor with nitrogen before each oxidation period. The carbon removal was incomplete during the first oxidation period ( 0.65 std. cu. ft./hr. of air; bed temperature $=1,015^{\circ} \mathrm{F}$.) with the exit gases containing $5.9 \%$ carbon dioxide at the end of an hour. During the second oxidation period ( $2.3 \mathrm{std}$. cu. ft./hr.; bed temperature $=1,020^{\circ}$ to $1,040^{\circ} \mathrm{F}$.), the removal of carbon was almost complete with the exit gases containing only $0.1 \%$ carbon dioxide at the end of an hour.

The reactor was cooled and the catalyst 
Table 7. Reproducibility of Results

$\begin{array}{ll}\text { Pressure: } & 30 \mathrm{~atm} . \\ \text { Feed rate: } & 5 \mathrm{std} . \mathrm{cu} \mathrm{ft} . / \mathrm{hr} . \\ \text { Space velocity: } & 0.20 \mathrm{~mole} /(\mathrm{hr} . \text { ) (sq. ft.) }\end{array}$

\begin{tabular}{lcccccr} 
& Temp., & \multicolumn{2}{c}{ Feed composition, \% } & \multicolumn{3}{c}{ Percentage in product } \\
Run & ${ }^{\circ} \mathrm{F}$. & $\mathrm{CO}$ & $\mathrm{H}_{2}$ & $\mathrm{CH}_{4}$ & $\mathrm{CO}_{2}$ & $\mathrm{H}_{2} \mathrm{O}$ \\
O3 & 1050 & 30.0 & 70.0 & 25.4 & 10.5 & 14.2 \\
T29 & 1058 & 28.9 & 69.8 & 25.0 & 9.7 & 14.4 \\
A13 & 1060 & 28.6 & 70.5 & 25.6 & 10.2 & 16.5 \\
A29 & 1060 & 29.0 & 70.0 & 24.3 & 9.5 & 16.8 \\
A2 & 1063 & 28.8 & 70.3 & 23.7 & 9.1 & 15.3 \\
A10 & 1063 & 28.5 & 70.6 & 23.4 & 9.8 & 15.1 \\
F7 & 1069 & 28.3 & 70.8 & 23.4 & 9.4 & 17.0 \\
P1 & 1070 & 29.0 & 70.0 & 24.8 & 9.8 & 16.0
\end{tabular}

removed after the second oxidation period. The usual black powder was not present in the bed. Some reddish-brown powder, presumably ferric oxide, was found. This iron oxide was not the result of oxidation of the steel but originated from the iron present in the unoxidized carbon deposit. The percentage of iron mixed with the carbon was always large enough to magnetize the powder removed from a used bed.

The catalyst was returned to the reactor after 27 days of exposure to the atmosphere at room temperature. The curves starting at approximately $53 \mathrm{hr}$. in Figure 18 show the effect of the long shutdown period on the catalyst activity.

Reproducibility of Results. Table 7 lists several runs made under approximately the same experimental conditions but with different batches of the C1013 catalyst. The results show a high degree of consistency, particularly so if allowances are made for the variations in temperature and feed concentration between the various runs.

\section{Mechanism Studies}

The identity of products obtained from $\mathrm{H}_{2}-\mathrm{CO}$ and $\mathrm{H}_{2}-\mathrm{CO}_{2}$ feeds and the fact that both reactions exhibit the same threshold phenomenon between $925^{\circ}$ and $1,025^{\circ} \mathrm{F}$. imply that the hydrogenations follow similar paths. The conversion of a major portion of the feed carbon oxide to the other carbon oxide suggests that the reactions relating the two oxides might be basic steps in these reaction paths.

To study that part of the over-all reaction which relates the two oxides, hydrogen was eliminated from the feed. Inert helium was used in its place to permit operation at $30 \mathrm{~atm}$. without changing the partial pressure of carbon oxide in the feed. The experimental conditions of the temperature traverses with $\mathrm{H}_{2}-\mathrm{CO}_{2}$ and $\mathrm{H}_{2}-\mathrm{CO}$ feeds (Figures 8 and 9) were duplicated to permit comparisons of the conversions of the carbon oxide with and without the presence of hydrogen.

He-CO Feed. The rate of formation of carbon dioxide from a $\mathrm{He}-\mathrm{CO}$ feed is compared in Table 8 with the rate obtained with a $\mathrm{H}_{2}-\mathrm{CO}$ feed.

\section{Table 8}

Carbon dioxide formation

Temperature rate, moles/(hr.)(sq. ft).

$\begin{array}{rcc}{ }^{\circ} \mathbf{F} . & \mathrm{H}-\mathrm{CO} \text { Feed } & \mathrm{He}-\mathrm{CO} \text { Feed } \\ 828 & 0.0006 & 0.00099 \\ 851 & 0.0009 & \\ \mathbf{9 5 0} & \mathbf{0 . 0 0 6 2} & 0.00875 \\ \mathbf{1 0 0 2} & \mathbf{0 . 0 1 2 1} & \\ \mathbf{1 0 4 2} & \mathbf{0 . 0 1 2 3} & 0.0223 \\ 1058 & 0.0123 & \end{array}$

The reaction which occurred with a $\mathrm{He}-\mathrm{CO}$ feed can be represented by the following stoichiometric equation:

$$
2 \mathrm{CO}=\mathrm{CO}_{2}+\mathrm{C}
$$

This reaction was catalyzed by the steel balls. It underwent the same increase in activity at the threshold temperature as the over-all reaction occurring with a $\mathrm{H}_{2}-\mathrm{CO}$ feed, indicating that the threshold phenomenon exists for the over-all hydrogenation reaction- because of an increase in the rate of this reaction in that temperature range.

The rate of carbon dioxide formation at $1,042^{\circ} \mathrm{F}$. with a $\mathrm{He}-\mathrm{CO}$ feed was approximately twice that with a $\mathrm{H}_{2}-\mathrm{CO}$ feed. However, the rate of carbon monoxide conversion was almost the same for both feeds, approximately 0.045 mole/(hr.) (sq. ft.). A reasonable explanation is the hydrogenation of some of the adsorbed carbon monoxide to methane. The hydrogenation occurring in this manner diverts part of the carbon from its destination of carbon dioxide and causes it to appear as hydrocarbons.

$\mathrm{He}-\mathrm{CO}_{2} \mathrm{Feed}$. The equilibrium for the reaction

$$
\mathrm{CO}_{2}=\mathrm{CO}+1 / 2 \mathrm{O}_{2}
$$

is such that no appreciable conversion of the carbon dioxide to carbon monoxide could be expected in the absence of hydrogen. The ratio $\left(\mathrm{CO}^{3 / 2} / \mathrm{CO}_{2}\right.$ at $980^{\circ}$ and $1,160^{\circ} \mathrm{F}$. is $3.3 \times 10^{-15}$ and $3.7 \times 10^{-13}$, respectively, at equilibrium. Evidence exists, however, that the conversion proceeded to some extent. The steel balls when removed from the reactor possessed the blue-black color of oxidized steel surfaces. The oxidation could have been due to the $0.1 \%$ oxygen in the feed gases or to the leakage of a small amount of air into the reactor during the cooling period. It is believed, however, that the bulk of the oxidation was due to the conversion of the carbon dioxide to carbon monoxide. The ability of carbon dioxide to oxidize steel is recognized in its classification as an oxidizing atmosphere in metallurgical operations.

Methane Feed. Pure methane was passed over a fresh batch of steel balls at $1,000^{\circ} \mathrm{F}$. No change in gas volume or traces of ethane in the exit gas stream could be detected. This indicated that the production of ethane was not dependent on the prior appearance of methane in the gas stream.

Hydrogen Feed. A feed stream of hydrogen was passed over a bed of used catalyst which had been operated under carbon-depositing conditions with a $\mathrm{H}_{2}-\mathrm{CO}$ feed for several hours. The bed was thoroughly flushed with nitrogen before the hydrogen was admitted. A small amount of methane was formed initially, probably from the carbon monoxide adsorbed on the catalyst, but the hydrogen did not appear to react with the carbon deposit.

\section{LITERATURE CITED}

1. Akers, W. W., and R. R. White, Chem. Engr. Progr., 44, 553 (1948).

2. Alberts, L. W., J. S. Bardin, D. W. Beery, H. R. Jones, and F. J. Vidt, Chem. Engr. Prog., 48, 486 (1953).

3. Anderson, R. B., J. F. Sehultz, B. Seligman, W. K. Hall, and H. H. Storch, J. Am. Chem. Soc., 72, 3502 (1950).

4. Binder, G. G., and R. R. White, Chem. Engr. Prog., 46, 563 (1950).

5. Breck, C. R., Gas, 28, No. 5, 44 (1922).

6. Dent, J. F., and D. Hebden, Gas J., 261, 160, 167 (1949).

7. Dew, J. N., Ph.D. thesis, Univ, Mich., Ann Arbor (1953).

8. Fischer, F., and H. Tropsch, Brennstoff-Chem., 4, 276 (1923).

9. Gilkeson, M., R. R. White, and C. M. Sliepcevich, Ind. Eng. Chem., 45, 460 (1953).

10. Gross, H. W., Erdöl u. Kohle, 3, 218 (1950).

11. King, J. G., Gas Research Board (British), No. GRB 67 (1952).

12. - - Gas World, 122, 196, 404 (1945).

13. Layng, E. T., U. S. Pat. 2,506,226 (May 2,1950 ).

14. Pursley, J. A., R. R. White, and C. M. Sliepcevich, Chem. Eng. Progr., 48, 51 (1952).

15. Sabatier, P., and J. B. Senderens, Compt. rend., 124, 1358 (1897).

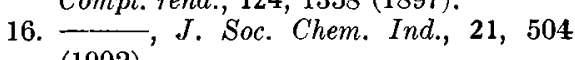
(1902).

17. Smith, B. D., Ph.D. dissertation, Univ. Mich., Ann Arbor (1954).

18. Storch, H. H., N. Golumbric, and R. B. Anderson, "The Fischer-Tropsch and Related Syntheses," John Wiley and Sons, Inc., New York (1951).

Presented at A.I.Ch.E. New York meeting 